\title{
A CAD Paradigm for Generating Woodworking Motifs
}

\author{
Vishal Gulati \\ GJ University of Science \& \\ Technology, Hisar, India
}

\author{
Kulwant Singh \\ GJ University of Science \& \\ Technology, Hisar, India
}

\author{
Puneet Katyal \\ GJ University of Science \& \\ Technology, Hisar, India
}

\begin{abstract}
In objective to preserve the cultural heritage of Saharanpur Art, this work presents an in-house CAD tool for generating Saharanpur's motifs. A fusion of traditional making methods and CAD technology has been presented which leads to a new methodology for creating Saharanpur's woodcrafts. With an inspiration to provide traditional emergence in woodcrafts, Saharanpur floral patterns have been used as an essential resource to archive decorative effects.
\end{abstract}

\section{Keywords}

CAD, Motif, Pattern

\section{INTRODUCTION}

Saharanpur in India can be easily and clearly searched for the history of its woodworking. It is one of the traditional centers for hand-crafted wood items. Saharanpur's woodcrafts are famous for its uniqueness, attractiveness, meticulousness and quality. Particularly, it is well-known for its unique style of floral motifs carved in low relief on the Sheesham wood (Figure 1).

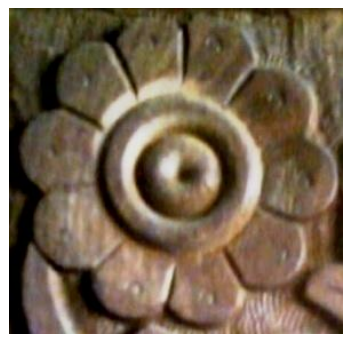

(a)

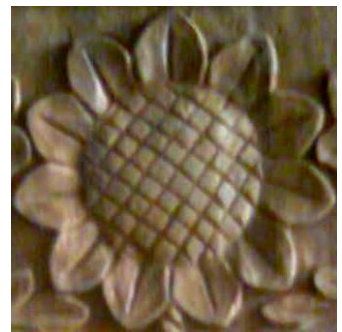

(c)

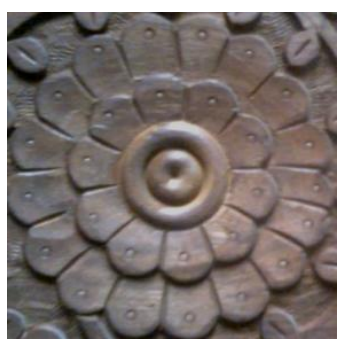

(b)

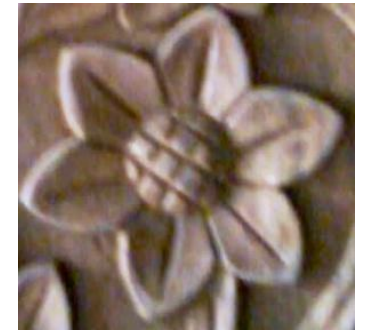

(d)
Fig 1: Saharanpur's floral motifs

Still, Saharanpur's woodcrafts are very popular worldwide, but many problems are arising due to its complex traditional making with hand, which is a time consuming task and requires much skill. Therefore, its traditional production is currently fading because new upcoming generations are not interested in. Moreover, there is no indigenous knowledge and skill of forebears to prolong this art form.
Several commercial design and graphics packages are available in the market, which can create this class of woodworking. But, local craftsmen are very resistant to accept new technology because of fear to lose the heritage style of woodworking. As a result, old design motifs are existing there for ages. Besides, commercial CAD packages are beyond the reach of craftsmen in terms of price as well as knowledge. Hence, this work presents a parametric CAD paradigm, which offers the possibility for assisting craftsmen in creating 2D designs. Firstly, this work understands the traditional design styles in order to preserve its cultural heritage and then develops an in-house CAD tool for generating Saharanpur's motifs. Using this tool, it is possible to make many more motifs and patterns in addition to contemporary design styles with lot of variation.

Automation is certainly not the goal, but the precedence is to provide a tool to the craftsmen for exploration of new motifs of their choice in the existing class. Furthermore, this work can provide a cost effective system for the handicraft workers to reproduce the identical woodwork in smaller time duration. Thus, woodcraft sector, which is growing leaps and bounds in this part of India, can be made economically sustainable by empowering it with the technological tools of design and manufacturing.

\section{LITERATURE}

Many attempts have been made to produce computergenerated decorative patterns by using the field of computer graphics, which offers many algorithmic possibilities for creating two-dimensional decorative patterns. A long time back, Chua [1] described a method for generating parametric patterns aligned along a circular arc. Kaplan [2] presented a process for creating computer-generated Islamic star patterns. Gulati [3-4] developed a parametric CAD modeler for creating star patterns to produce traditional piece of latticeworked screens. Shrivastva [5] made an attempt to develop parametric traditional Rangoli and Phulkari patterns. Trivadi [6] presented an application of CAD for producing Moradabad brassware patterns. Wong [7] described and explored the ways in which floral patterns can be created algorithmically. Kedar [8] proposed a design software for generating 2D floral border patterns. Anderson [9] created beautiful ornamental 2D patterns, which follows a userdefined curve.

\section{MODELING OF A SAHARANPUR FLORAL MOTIF}

This section presents an approach for parametric modeling of a Saharanpur's floral motif (Figure 1d).

Traditionally, compass drafting is being used to draw such a type of floral motif (Figure 2). It is drawn with the aid of two co-centric circles of different radius. These circles can be divided into a number of sectors equal to the petals required in the floral motif. For instance, the sector OIBAJ in Figure 3 is 
utilized to draw the petal geometry (IBCAJ) which consist three $\operatorname{arcs}(\mathrm{BC}, \mathrm{CA}$ and JI) and two lines (IB and AJ). Points $\mathrm{I}, \mathrm{J}, \mathrm{B}$ and $\mathrm{A}$ lie on the two circles and point $\mathrm{C}$ is the intersection of two arcs of radius equal to the segment $\mathrm{AB}$.

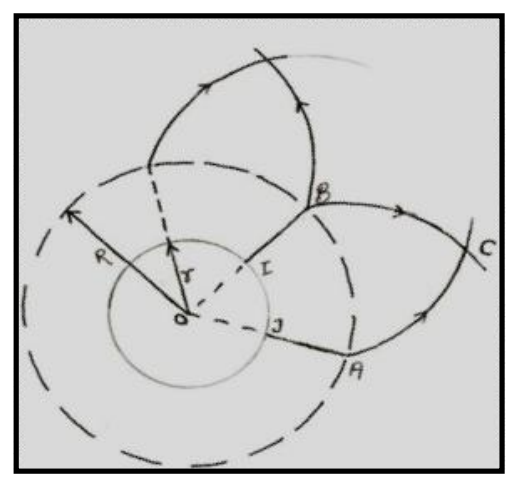

Fig 2: A Traditional drawing of the motif

During CAD modeling, this floral motif is viewed as an array of primitive (the petal shown with red color in Figure 3b) which is an atomic geometric object made from 2D entities such as line and arc. It is in the form a planar map having a set of points whose coordinates have been devised in terms of the following intuitive modeling parameters (Figure 3c).

- $\quad$ Number of petals (n) in the floral motif

- Size of the motif defined by the radius (R) of outer circle

- Size of central circular part of the motif defined by the radius ( $r$ ) of inner circle

Table 1 shows coordinates of the points in terms of modeling parameters. The idea here is to create a variety of floral motifs in this class by defining the modeling parameters. Figure 4 shows such a variation in this class of motifs.

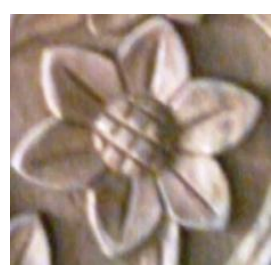

(a)

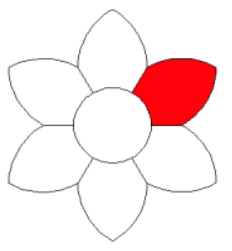

(b)

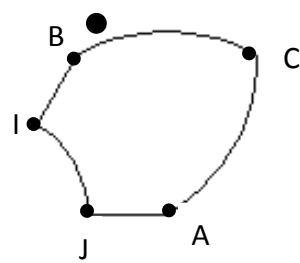

(c)
Fig 3: Primitive's geometry

\section{PATTERN GENERATION}

The appeal of Saharanpur geometric decoration lies in its logical interrelation of motifs. Patterns are composed of motifs which are multiplied and ordered in regular sequences by using transformations between them. The role of transformations is to define positions of the motifs with respect to pattern in a 2D plane. Motifs are placed in a pattern with a special theme e.g. aligning motifs along a specified path or in a rectangular array (Figure 5). Different styles of contemporary Saharanpur patterns have also been produced using this paradigm (Figure 6).

Table 1: Coordinates of the points in the primitive

\begin{tabular}{|c|l|}
\hline Points & \multicolumn{1}{|c|}{ Position of the Points } \\
\hline $\mathbf{I}$ & $r \operatorname{Cos} \frac{2 \pi}{n}, r \operatorname{Sin} \frac{2 \pi}{n}$ \\
\hline $\mathbf{B}$ & $R \operatorname{Cos} \frac{2 \pi}{n}, R \operatorname{Sin} \frac{2 \pi}{n}$ \\
\hline $\mathbf{C}$ & $2 R \operatorname{Cos} \frac{\pi}{n} \operatorname{Sin} \frac{6 \pm n}{6 n} \pi, 2 R \operatorname{Sin} \frac{\pi}{n} \operatorname{Sin} \frac{6 \pm n}{6 n} \pi$ \\
\hline $\mathbf{A}$ & $\mathrm{R}, 0$ (assumed) \\
\hline $\mathbf{J}$ & $\mathrm{r}, 0$ (assumed) \\
\hline
\end{tabular}
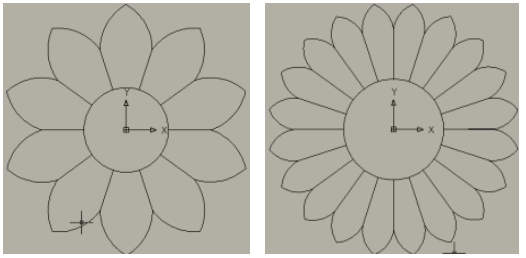

$\mathrm{n}=10, \mathrm{R}=50, \mathrm{r}=25$
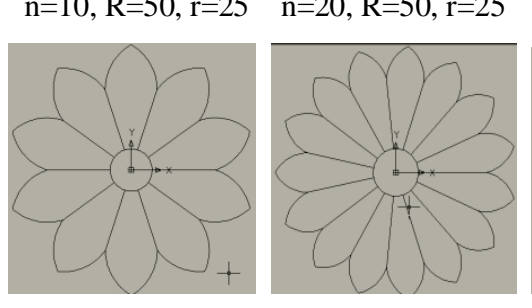

$n=10, R=100, r=25 \quad n=15, R=100, r=25$

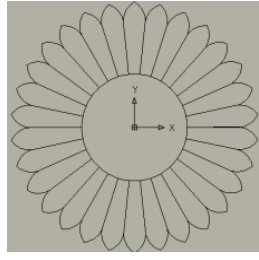

$\mathrm{n}=30, \mathrm{R}=50, \mathrm{r}=25$

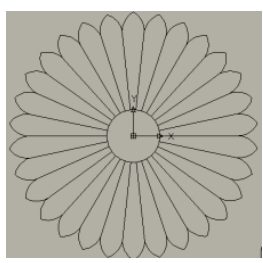

$n=30, R=100, r=25$

Fig 4: Parameterized floral motifs

\section{IMPLEMENTATION}

This work has been implemented under the ActiveX and Visual Basic Application (VBA) programming environment using AutoCAD. VBA runs in the same process space as AutoCAD which provides programmable control through the ActiveX Automation interface. By putting the modeling parameters, decorative patterns can be rendered.

\section{CONCLUDING REMARKS}

This work presents a methodology for creating Saharanpur's woodcrafts through fusion of computer aided geometric modeling and traditional manufacturing methods. The presented work is a convergence of craft and technology. It is an indication of the way how traditional craft skills of woodworking and technologies can be engaged. This paradigm complements Saharanpur wood working production techniques by means of understanding, adapting and designing its traditional production, thus provides the craftsmen with a CAD tool for designing and manufacturing. 


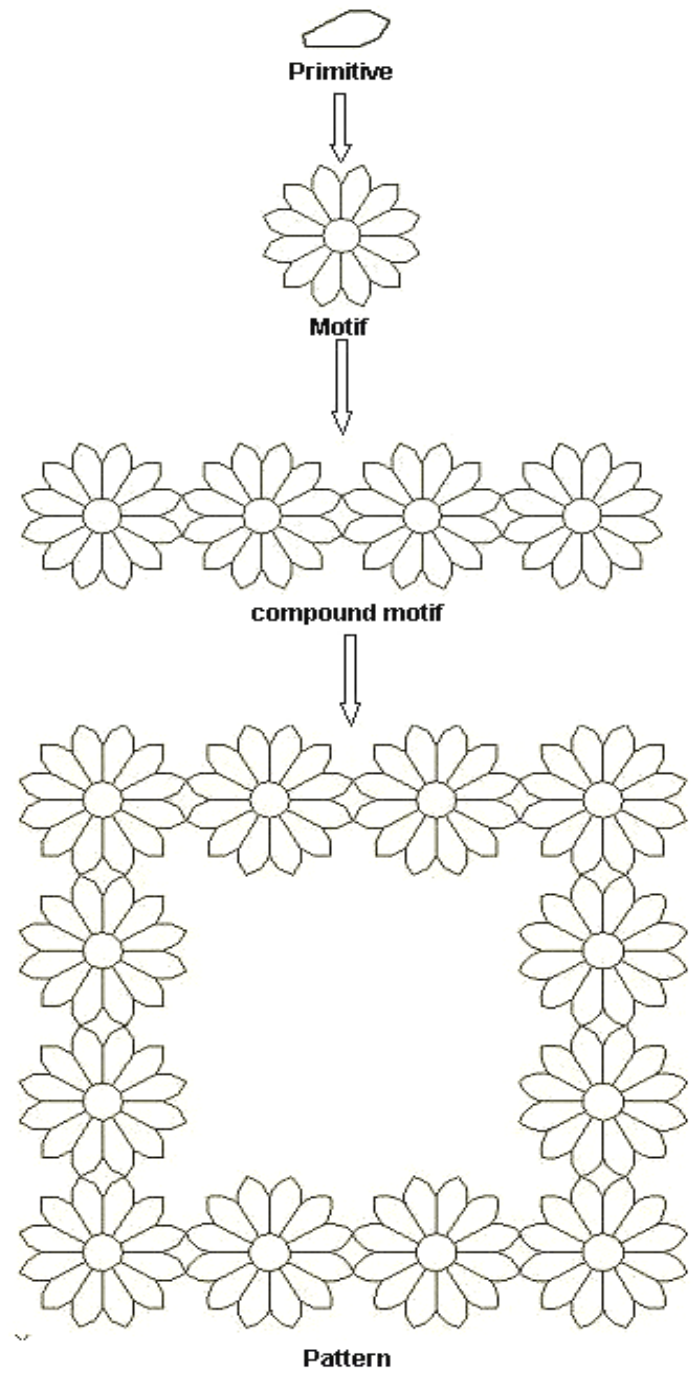

Fig 5: Hierarchical levels to generate pattern

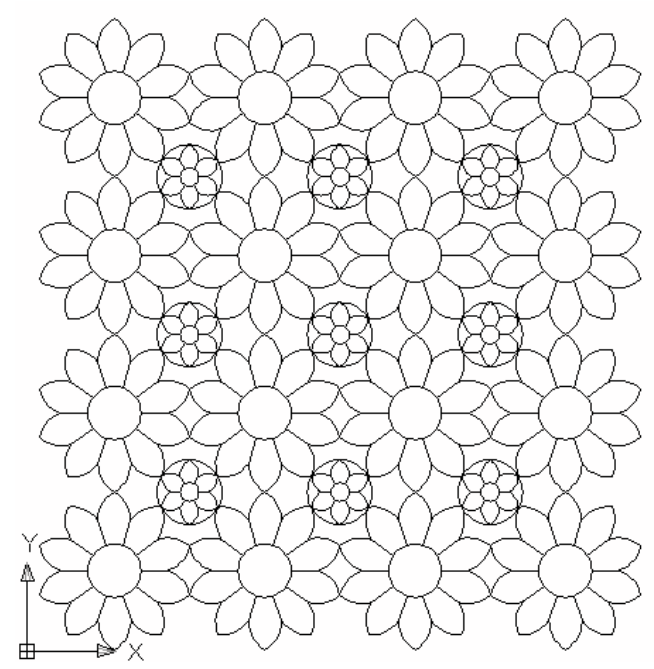

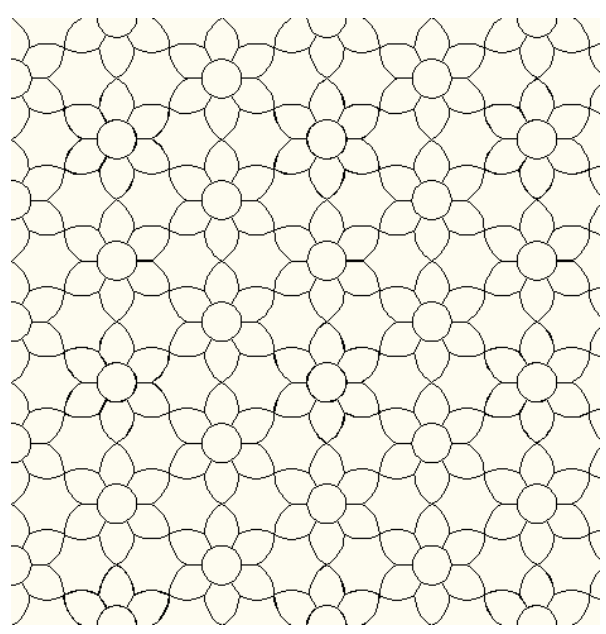

Fig 6: Contemporary Saharanpur patterns

\section{REFERENCES}

[1] Chee Kai Chua, Robert Gay and Wolfgang Hoheisel , "A Method of Generating Motifs Aligned Along a Circular Arc", Computer \& Graphics, Vol. 18, No. 3, pp. 353362, 1994.

[2] Kaplan C. S. "Computer Graphics and Geometric Ornamental Design", Ph.D., University of Washington, Seattle, 2002.

[3] Vishal Gulati and Puneet Katyal, "Parameterized Modeling of Star Patterns for Traditional Latticed Screens", International Journal of Computer Applications, Vol. 11, No.1, 2010.

[4] Vishal Gulati, Puneet Tandon, Hari Singh, "A CAD Paradigm to Produce Zillij Style of Geometrical Patterns for Wooden Carvings", International Journal of Computer Applications Vol. 3, No.3, 2010.

[5] Rahul Shrivastva, "Customization of CAD Modelling Software Using Parametric Macros for Design of Machinable Artistic Surface Patterns", M-Tech thesis, Thaper University Patiala, India, 2009.

[6] Trivedi S., Tiwari A., Chatterjee A., Pathak V., Dhande S. G. and Chauhan D. S., "Application of CAD, Rapid Prototyping and Reverse Engineering in Handicrafts Sector - A Success Story", 9th International Conference on Engineering Education, July 2006.

[7] Michael T. Wong, Douglas E. Zongker and David H. Salesin, "Computer-Generated Floral Ornament", University of Washington.

[8] Kedar S. P.," Geometric Modeling of Patterns", Master's thesis, Department of Computer Science and Engineering, Indian Institute of Technology, Kanpur, India, 2009.

[9] Dustin Robert Anderson, "Two-dimensional Computergenerated Ornamentation Using a User-driven global planning strategy", Master of Science in Computer Science, Thesis, California Polytechnic State University, San Luis Obispo, 2007

[10] Vishal Gulati and Puneet Katyal," A Hierarchic Representation Scheme For Generating Decorative Pattern"s, International Journal of Current Research Vol. 3, Issue, 11, pp.186-189, October, 2011. 